\title{
PHYSIQUE AND BODY COMPOSITION OF GIRLS PRACTISING CONTEMPORARY DANCE
}

\author{
KAROLINA H. PRZEDNOWEKIA, DOROTA KOPEĆ'BB, ANNA WALASZCZYK-ISKRA² \\ ${ }^{1}$ University of Rzeszów, Faculty of Physical Education, Department of Historya, \\ Department of Individual Sports ${ }^{b}$ \\ 2 Jerzy Kukuczka Academy of Physical Education in Katowice, Faculty of Physical Education, \\ Department of Correction of Body Posture Imperfections
}

\author{
Mailing address: Karolina H. Przednowek, University of Rzeszów, Faculty of Physical Education, \\ 3 Towarnickiego Street, 35-959 Rzeszów, tel.: +48 17 8721854, fax: +48 17 8721861, e-mail: karprzed@ur.edu.pl
}

\begin{abstract}
Introduction. Physique and body composition are often explored in sport-related research. This is due to the fact that morphological features can be useful for determining a person's predispositions for practising a given type of physical activity. Dance, as any other sports discipline, has an impact on the physique and motor skills of those who practise it. Most research concerning the physique and body composition of dancers conducted so far has focused on persons practising ballet or competitive ballroom dancing. Investigating these issues in contemporary dancers is a new field of study. The aim of the current study was to examine the physique and body composition of girls aged 14-17 years practising contemporary dance. Material and methods. The study involved 23 girls who trained contemporary dance twice a week for 2 hours. The participants of the study had been training since the age of six. Basic anthropometric measurements were performed. Body composition was analysed based on parameters measured using a Tanita body composition analyser. Conclusions. The analysis found that girls training contemporary dance were characterised by a leptosomatic physique. BMI values in both younger and older contemporary dancers indicated that their weight was normal. Compared to girls who did not practise any particular type of sport, contemporary dancers had a lower weight, a lower body water percentage, and a lower body fat percentage. The dancers were also characterised by a greater circumference of the waist, hips, arm, and chest compared to untrained peers.
\end{abstract}

Key words: physique, body composition, contemporary dance

\section{Introduction}

Physical activity is considered to be one of the most important factors determining health and physical fitness [1]. Regular physical exercise not only causes a decrease in the amount of fatty tissue, an increase in muscle mass, and a strengthening of the bones and joints, but also an increase in heart muscle mass, a reduction in blood pressure, a decrease in heart rate, and a slowing of respiratory rhythm $[2,3]$.

One of the most popular types of physical activity is dance. The therapeutic benefits of engaging in this traditional form of movement, which has been practised for centuries, have been reported for several years. Garbacik and Węgrzyn [4] describe choreotherapy, that is treatment involving dance and its elements, as one of the forms of movement therapy. The therapeutic function of dance consists in the fact that it enhances one's motor coordination, general physical condition, body image, and mood and well-being, as well as improving body awareness $[4,5,6]$. A study conducted by a research group from the Faculty of Medicine at the University of Rzeszów showed that choreotherapy can have a significant impact on stimulating development in the emotional and social spheres in children with psycho-motor retardation [7].

Apart from impacting the psychological sphere, dance also has a positive influence on the physical sphere. As any other sports discipline, physical activity related to dance can alter the body, that is one's figure, physical fitness, and motor skills $[8$, $9,10]$.

Many authors have explored issues having to do with physique and body composition. Krakowiak et al. [11] examined athletes who practised short-distance running and established that the body type that dominated among them was the mesomorphic type. Similar results were obtained regarding the body types of judoists [12]. On the other hand, research performed by Kozłowska et al. [3] on a group of female junior combat sports athletes showed that they had a leptosomatic body type. This was also observed in Pilewska et al.'s [14, 15, 16] research, where a group of dancesport athletes practising different styles were examined: most dancers had slim bodies. Artistic gymnasts were classified as having a slender body type, as well, in a study by Poliszczuk et al. [17]. Nowacka-Chiari [18], who compared the physique of young female swimmers with that of persons who did not train any sports, found that girls practising swimming had specific physical features. In a study of basic auxological parameters of students of physical education, Smolarczyk et al. [19] found that these young people were characterised, among others, by a greater body height and weight compared to the general population. Another group of young persons practising sports whose physique has been analysed is volleyball players: Pezala et al.s [20] study involved a group of 14-year-old 
female players. Moreover, Pietraszewska et al. [21] investigated the amount and distribution of body fat in professional soldiers and police officers. Their analysis showed that police officers had a higher body fat level and a greater tendency for abdominal obesity compared to professional soldiers.

As far as research concerning dancers is concerned, Pilewska et al. were some of the authors who examined their physique. Pilewska et al.'s $[15,22]$ research involved male and female dancers of the Latin style who were highly trained. Similar research was conducted using bioelectrical impedance on a group of professional dancers from a dance school in Athens by Greek researchers [23]. Researchers from Serbia, on the other hand, used bioelectrical impedance to determine BMI values and body fat levels in a group of female ballet dancers [24]. The physique and body composition of female dancers practising ballet were also studied by Mihajlović et al. [25], and body fat percentage was examined in 112 female ballet dancers aged 15 years and 33 male ballet dancers aged 18 years by researchers from Houston [26]. Moreover, a group of researchers from the University of Zagreb carried out a study exploring the physique and body composition of 15 soloists and 15 members of the corps de ballet from the Croatian National Theatre Ballet [27].

Since most of the research concerning physique and body composition involving dancers conducted so far has examined dancers practising ballet or dancesport, carrying out such analyses in contemporary dancers is a new area of investigation in the field. The aim of the current study was thus to examine the physique and body composition of girls aged $14-17$ years practising contemporary dance.

\section{Material and methods}

The research was conducted in June 2016 on a group of 23 girls aged $14-17$ years. The subjects participated in regular contemporary dance classes, held twice a week for 2 hours. As the dancers had been dancing since the age of six, they were divided into two age groups: the younger one, consisting of dancers aged $14-15$ years $(n=12)$, and the older one, composed of dancers aged $16-17$ years $(\mathrm{n}=11)$. The following anthropometric parameters were measured: height; weight; sitting height; waist, hip,

Table 1. Anthropometric indices of girls practising contemporary dance

\begin{tabular}{|c|c|c|}
\hline Index & Classification & Formula \\
\hline \multirow{4}{*}{$\mathrm{BMI}^{*}(3-18$ years $)$} & Underweight: $<5$ th percentile & \multirow{4}{*}{ [Weight in kg/height2 in m] } \\
\hline & Normal weight: 5th-85th percentile & \\
\hline & Overweight: 85th-95th percentile & \\
\hline & Obesity: > 95th percentile & \\
\hline \multirow{3}{*}{$\begin{array}{l}\text { Rohrer index } \\
\text { (classification based on Kowalewska) }\end{array}$} & Leptosomatic type: $\mathrm{x}-1.22$ & \multirow{3}{*}{ [Weight in $\mathrm{g} /$ height $^{3}$ in $\mathrm{cm}$ ] $\times 100$} \\
\hline & Athletic type: $1.23-1.43$ & \\
\hline & Pyknic type: $1.44-x$ & \\
\hline \multirow{3}{*}{ Marty index } & Small circumference: $x-39.0$ & \multirow{3}{*}{ [Chest circumference at height $x i$ in $\mathrm{cm} /$ height in $\mathrm{cm}$ ] $\times 100$} \\
\hline & Average circumference: 39.1-45.6 & \\
\hline & Large circumference: $45.7-x$ & \\
\hline \multirow{3}{*}{ Skerlj index } & Thin: $x-32.4$ & \multirow{3}{*}{ [Thigh circumference/height] $\times 100$} \\
\hline & Of medium build: $32.5-36.7$ & \\
\hline & Corpulent 36.8-x & \\
\hline \multirow{6}{*}{ Pignet index } & Very strong: $x-9.9$ & \multirow{6}{*}{ Height - [chest circumference at rest + weight] } \\
\hline & Strong: $10-15.9$ & \\
\hline & Good: $16-20.9$ & \\
\hline & Weak: 21-30.9 & \\
\hline & Very weak: $31-35.9$ & \\
\hline & Poor: $36-x$ & \\
\hline \multirow{3}{*}{ Chest to hip circumference ratio } & Masculine proportions: $91.8-98.4$ & \multirow{3}{*}{ [Chest circumference/hip circumference] x 100} \\
\hline & Feminine proportions: $76.6-84.6$ & \\
\hline & Intermediate proportions: 84.7-91.7 & \\
\hline \multirow{5}{*}{ Oeder index } & Very poor: $\mathrm{x}-83$ & \multirow{5}{*}{ [Actual weight/theoretical weight] $\times 100$} \\
\hline & Poor: 83.01-87.53 & \\
\hline & Medium: 87.54-96.57 & \\
\hline & Good: 96.58-101.1 & \\
\hline & Very good: 101.11-x & \\
\hline
\end{tabular}

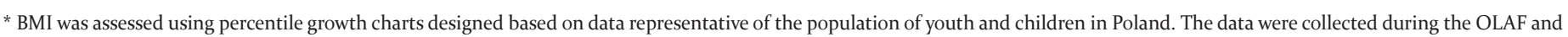
OLA projects, coordinated by the Children's Memorial Health Institute, in the years 2007-2012. 
thigh, and arm circumferences; as well as chest circumference at rest and during maximal inspiration and expiration. Body composition was analysed based on the following parameters measured using a Tanita MC-980 Body Composition Analyzer: BMR (Basal Metabolic Rate in kcal), FAT (body fat amount in \% and $\mathrm{kg}$ ), FFM (fat-free mass), and TBW (total body water). Based on the values of the parameters, the following anthropometric indices were calculated: the Body Mass Index (ratio of weight to height), the Rohrer index (assessing body type), the Marty index (assessing chest circumference), the Skerlj index (ratio of greatest thigh circumference to height), the Pignet index (assessing body build using chest circumference, weight, and height), the chest to hip circumference ratio, and the Oeder index (assessing nutritional status) [28]. Owing to the fact that all the subjects in the study were female, the classifications presented in Table 1 refer to women only.

The data collected in the study were presented in tables. Arithmetic means, standard deviations, and coefficients of variation were calculated. The statistical significance of the differences between the values obtained for the two age groups was then measured using ANOVA.

\section{Results}

Table 2 shows the values of particular parameters of physique and body composition recorded for the participants of the study, divided into two age groups. The study showed that the weight of the girls in the two groups was similar and only slightly higher in the case of the older group (51.4 kg for girls aged 1415 years and $51.9 \mathrm{~kg}$ for those aged 16-17 years). A similar observation was made for height $(162.3 \mathrm{~cm}$ for the younger group and $164.2 \mathrm{~cm}$ for the older group) and sitting height $(82.6 \mathrm{~cm}$ and $85.8 \mathrm{~cm}$ for the two groups, respectively). Minor differences were also noted in the measurements of waist, hip, thigh, and arm circumferences. However, an analysis of the results for these parameters showed that younger girls were characterised by a higher waist $(71.5 \mathrm{~cm})$ and arm $(25.9 \mathrm{~cm})$ circumference than older ones $(68.5 \mathrm{~cm}$ and $25.7 \mathrm{~cm}$, respectively). The differences were statistically significant only when it came to sitting height.

The highest differences between the two age groups were observed with regard to weight. When it comes to BMI values, younger girls were characterised by higher values of this parameter (19.5) than older ones (19.2). Girls aged 14-15 years also had higher values of the coefficient of variation. An additional analysis showed that the differences in the BMI values of the two groups were statistically significant.

The values of the Rohrer index recorded for the two groups showed that regardless of the age group, the girls were characterised by a leptosomatic physique. The results obtained for the Skerlj index were similar: based on the values of 31.8 (for girls aged $14-15$ years) and 31.6 (for those aged 16-17 years), the subjects could be classified as thin. As far as the Pignet index is concerned, it amounted to 29.7 for younger girls and 31.3 for older

Table 2. Physique and body composition of girls practising contemporary dance with respect to the two age categories

\begin{tabular}{|c|c|c|c|c|c|c|c|c|c|c|c|c|}
\hline \multirow{2}{*}{ Variables } & \multicolumn{5}{|c|}{ Age: $14-15$ years } & \multicolumn{5}{|c|}{ Age: $16-17$ years } & \multirow{2}{*}{ d } & \multirow{2}{*}{$p$} \\
\hline & $x$ & $s$ & V & $\min$ & $\max$ & $x$ & $S$ & V & $\min$ & $\max$ & & \\
\hline Weight & 51.4 & 7.4 & 14.3 & 36.9 & 62.7 & 51.9 & 5.8 & 11.2 & 41.4 & 61.9 & -0.5 & 0.854 \\
\hline Height & 162.3 & 6.3 & 3.9 & 150.0 & 172.0 & 164.2 & 6.8 & 4.1 & 153.0 & 179.0 & -1.8 & 0.505 \\
\hline Sitting height & 82.6 & 3.3 & 4.0 & 78.0 & 88.0 & 85.8 & 3.4 & 4.0 & 79.0 & 92.0 & -3.2 & $0.032^{*}$ \\
\hline Waist circumference & 71.5 & 6.4 & 9.0 & 60.0 & 84.0 & 68.5 & 3.9 & 5.7 & 63.0 & 73.0 & 3.0 & 0.187 \\
\hline Hip circumference & 92.2 & 6.0 & 6.6 & 78.0 & 99.0 & 93.2 & 4.2 & 4.5 & 88.0 & 99.0 & -1.0 & 0.649 \\
\hline Thigh circumference & 51.6 & 4.1 & 7.9 & 43.0 & 56.0 & 51.9 & 2.7 & 5.3 & 47.0 & 57.0 & -0.3 & 0.825 \\
\hline Arm circumference & 25.9 & 2.9 & 11.1 & 21.0 & 30.0 & 25.7 & 1.3 & 5.2 & 23.0 & 27.0 & 0.2 & 0.844 \\
\hline BMI & 19.5 & 2.3 & 11.8 & 15.4 & 23.0 & 19.2 & 1.4 & 7.2 & 16.4 & 21.3 & 0.2 & 0.784 \\
\hline BMR (kcal) & 1387.6 & 82.7 & 6.0 & 1208.0 & 1495.0 & 1397.8 & 77.4 & 5.5 & 1288.0 & 1553.0 & -10.2 & 0.763 \\
\hline Fat percentage & 22.3 & 6.3 & 28.5 & 11.7 & 28.8 & 17.1 & 4.2 & 24.6 & 8.6 & 22.8 & 5.1 & $0.034^{*}$ \\
\hline Fat mass $(\mathrm{kg})$ & 11.8 & 4.4 & 37.5 & 4.9 & 16.7 & 9.1 & 2.9 & 32.4 & 3.6 & 13.0 & 2.7 & 0.104 \\
\hline FFM & 39.6 & 4.0 & 10.0 & 30.4 & 46.0 & 42.8 & 3.3 & 7.8 & 37.8 & 49.9 & -3.2 & $0.049^{*}$ \\
\hline TBW percentage & 29.0 & 2.9 & 10.0 & 22.3 & 33.7 & 31.4 & 2.4 & 7.7 & 27.7 & 36.5 & -2.4 & $0.048^{*}$ \\
\hline Rohrer index & 1.20 & 0.1 & 11.9 & 0.9 & 1.4 & 1.17 & 0.1 & 8.3 & 1.0 & 1.4 & 0.0 & 0.603 \\
\hline Marty index & 50.0 & 3.1 & 6.3 & 45.9 & 55.3 & 49.4 & 3.1 & 6.4 & 45.8 & 55.6 & 0.6 & 0.630 \\
\hline Skerlj index & 31.8 & 2.2 & 6.9 & 28.7 & 35.0 & 31.6 & 1.5 & 4.7 & 29.6 & 33.5 & 0.1 & 0.861 \\
\hline Pignet index & 29.7 & 10.8 & 36.3 & 14.3 & 47.0 & 31.3 & 7.5 & 24.0 & 18.6 & 42.6 & -1.6 & 0.690 \\
\hline Chest to hip circumference ratio & 88.2 & 4.1 & 4.7 & 82.6 & 96.7 & 86.9 & 3.2 & 3.7 & 83.9 & 93.4 & 1.2 & 0.437 \\
\hline Oeder index & 85.8 & 9.7 & 11.3 & 70.0 & 104.5 & 83.9 & 7.4 & 8.8 & 70.2 & 95.6 & 1.9 & 0.601 \\
\hline
\end{tabular}

* statistically significant differences at the level of $\mathrm{p}=0.05$. 
ones, which means that the former had a weak physique and the latter had a very weak one.

Body proportions were assessed by means of the chest to hip circumference ratio. Higher values of this parameter were found for the younger group (88.2). Thus, the proportions of the bodies of the 14- to 15-year-olds who participated in the study were more masculine than those recorded for older girls; in the latter group, this parameter amounted to 86.9, indicating more feminine proportions.

Chest size was assessed based on the Marty index. The results of the measurement showed that the participants, regardless of age, were characterised by a large chest circumference. At the same time, it was noted that 14- to 15-year-olds had somewhat higher Marty index values (50.32) than older girls.

The body composition analysis showed that younger girls had more body fat, that is $11.8 \mathrm{~kg}$, which accounted for $22.3 \%$ of their weight. In the group of older girls, the FAT index was $9.1 \mathrm{~kg}$, that is $17.1 \%$ of their weight. In both cases, the values recorded were within the normal range. As far as the FFM (fatfree mass) index is concerned, it was higher in older girls, in whom it amounted to $42.8 \mathrm{~kg}$. In younger girls, on the other hand, fat-free mass was $39.6 \mathrm{~kg}$. Similar observations were made in the analysis of TBW (total body water) values: these values were higher in older girls (42.8) than in younger ones (29.0).

The value of BMR (basal metabolic rate) was somewhat higher in the older group than in the younger one, and it amounted to $1397.8 \mathrm{kcal}$ and $1387.6 \mathrm{kcal}$, respectively. Finally, when it comes to the Oeder index, according to the classification of Nowicka, the participants had a poor nutritional status. This was observed for both age groups, although younger girls had slightly higher values of this parameter.

\section{Discussion}

Morphological features have been the subject of research for many years. Physique and body composition depend not only on age, gender, or race but also on the level of physical activity. Many researchers who explored the impact of physical activity on the development of the human body have found that adequate levels of physical activity can impact the process of growth and development $[29,30]$.

In the current study, length parameters, such as height and sitting height, were the greater, the older the participants were. The same observations were made regarding weight. The results of the study were compared with those of the research performed by Nowak [31] on a group of untrained girls from the Subcarpathian region in Poland. A comparative analysis of the results of her study and the current one showed that there were no major differences in height between girls who did not train any sports and contemporary dancers [31]. The mean values for height in the girls from the Subcarpathian region were $161.9 \mathrm{~cm}$ (14-year-olds), $162.5 \mathrm{~cm}$ (15-year-olds), $164.5 \mathrm{~cm}$ (16-year-olds), and $164.7 \mathrm{~cm}$ (17-year-olds), whereas those for the contemporary dancers were $162.3 \mathrm{~cm}$ (14- to 15-year-olds) and $164.2 \mathrm{~cm}$ (16- to 17-year-olds). When it comes to weight, the results of the two studies were different. Dancers had a lower weight compared to their untrained peers. In the group of dancers aged $14-15$ years, mean weight was $51.4 \mathrm{~kg}$, whereas in the non-dancers in the other study, it was $52.3 \mathrm{~kg}$ (14-year-olds) and $54.1 \mathrm{~kg}$ (15-year-olds). As far as older dancers are concerned, the mean value of this parameter for the 16- to 17-year-olds in our study amounted to $51.9 \mathrm{~kg}$, whereas in untrained girls, it was $55.4 \mathrm{~kg}$ (16-year-olds) and $56.3 \mathrm{~kg}$ (17-year-olds) [31].
The analysis of the BMI values recorded in the current study showed that contemporary dancers from both age groups were characterised by normal weight. Similar findings were obtained for male and female ballet dancers from the Croatian National Theatre Ballet [27]. On the other hand, BMI values that were significantly lower than normal ones were noted by Serbian researchers who studied a group of 30 female ballet dancers: according to the classification of BMI levels, $50 \%$ of those ballet dancers were underweight [24]. Low BMI values were also found for female ballet dancers examined in the research performed by Dutch and Finnish researchers, who found significantly lower BMI values in dancers than in the control group (18.9 vs. 21.3, respectively) [32].

Slightly lower BMI values were observed in our female contemporary dancers than in untrained girls examined in the research carried out by Perenc et al. [33] and Burdukiewicz et al. [34]. In the group of 16- and 17-year-old girls from Rzeszów, BMI values were 21.1 and 24.3, respectively [33], whereas in our study, the mean value for the older group amounted to 19.2. Likewise, 16- and 17-year-old girls from Wrocław were characterised by higher BMI values compared to contemporary dancers in the older group in the current study [34].

The measurements of circumferences in the group of contemporary dancers showed that younger dancers had larger circumferences of the waist and arm than older girls. An analysis of the results of the measurements of thigh and hip circumferences, however, showed that these values were higher in 16to 17-year-olds. Compared to the untrained population from Wrocław, contemporary dancers were characterised by significantly higher circumferences of the waist, hips, and arm. In the case of thigh circumference, only untrained girls aged 16 and 17 years had higher values of this parameter than our subjects [34].

The dancers' physique was also assessed based on the Rohrer index, using Kowalewska's classification. Our subjects were found to have a leptosomatic physique. Similar results were obtained by Pilewska in a study involving a group of Latin style dancers. Approximately $60 \%$ of the dancers had a leptosomatic physique, whereas the remaining $40 \%$ had an athletic one [22]. A leptosomatic physique was also observed in female standard style dancers [16]. However, a comparison of Rohrer index values obtained for contemporary dancers with those of untrained girls from Rzeszów [31] revealed that our dancers had a slightly lower value of this parameter. Mean values of the Rohrer index in the comparative group were 1.23 (14-year-olds), 1.26 (15-yearolds), 1.24 (16-year-olds), and 1.26 (17-year-olds) [31]; on the other hand, in the group of younger dancers in the current study, this value amounted to 1.20 , and in the older group, it was 1.17. Similar observations were made when comparing the results of our study with those obtained by Burdukiewicz et al. [34]. This means that contemporary dancers had more slender bodies than their untrained peers.

Different conclusions were reached by Lourens, who investigated the body type of ballet dancers with respect to the number of hours they spent training. Her study showed that over $1 / 3$ of dancers who trained more than 10 hours per week had an endomesomorphic body type, while those who trained less than 10 hours per week tended to have an endoectomorphic one [35].

The subjects' physique was also examined using the Pignet index, which is calculated based on chest circumference, weight, and height. Based on the values of this index, younger girls were characterised by weak physique and older ones by a very weak one. 
The results of the measurement of chest circumference showed that the dancers examined in the study had large chests. The chests of contemporary dancers were much larger than those of their untrained peers who were involved in the study carried out by Burdukiewicz et al. [34]. Our findings are probably due to the influence of regular physical activity on the respiratory system.

Body composition consists of fat-free mass (FFM) - that is the mass of the muscles, organs, and bones - and fat mass. In the current study, the amount of fat-free mass was the highest in older dancers $(42.8 \mathrm{~kg})$. Dancers from this age group were also characterised by a smaller amount of fat mass (17.1\%). Similar research regarding body composition performed using bioelectrical impedance was carried out among professional dancers from a dance school in Athens; the mean amount of fat-free mass in the bodies of the Greek dancers was $42.6 \mathrm{~kg}$, and the body fat percentage was $19.4 \%$ [23]. Different results, however, were recorded by researchers from Houston who examined the body composition of 15-year-old female ballet dancers and 18-year-old male ballet dancers: their analysis showed that the mean body fat percentage was $20.1 \%$ in female dancers and only $14.5 \%$ in the group of male dancers [26]. Other research showed that the level of body fat in male dancers depended on the role they played in the ballet group. A study involving 15 soloists and 15 members of the corps de ballet from the Croatian National Theatre Ballet revealed that soloists were characterised by a significantly lower fat mass and a greater amount of fat-free mass compared to the latter group [27].

Burdukiewicz et al. [36] examined the body composition of, among others, 14- and 15-year-old girls. One of the parameters that were measured was the amount of body fat. Compared to the results obtained for untrained girls in that study, the contemporary dancers in the current study had considerably less fat mass. The amount of fat mass in our dancers was $22.3 \%$ (14- to 15 -year-olds), whereas in the comparative group, it was $26.5 \%$ (14-year-olds) and 28.0\% (15-year-olds) [36]. As far as the FFM index is concerned, it was on a similar level in both dancers and untrained persons. In the 16-year-olds from Łódź, the FFM value was $43.0 \mathrm{~kg}$, while in the older dancers in our study, it amounted to $42.3 \mathrm{~kg}$ [37].

Apart from fat-free mass and fat mass, it is also worth examining the total amount of water in the body (TBW). The norm for women aged $15-30$ years ranges from $47 \%$ to $57 \%$. The analysis of the amount of water in the bodies of our subjects showed that both age groups had a level of body water that was too low (29\% in 14 - to 15 -year-olds and $31.4 \%$ in 16 - to 17 -yearolds). These results indicating that contemporary dancers did not consume enough water contrasted with those reported for their peers, as untrained 16-year-olds were found to have $54.6 \%$ of water in their bodies by previous authors [37].

\section{Conclusions}

1. According to the results of the current study, girls practising contemporary dance are characterised by a leptosomatic physique. Based on the Skerlj index, they could be classified as thin.

2. We found that compared to girls who did not practise this sports discipline, contemporary dancers were characterised by a lower amount of fat mass; greater circumferences of the waist, hips, and arm; as well as a larger chest circumference.

3. Regardless of the age group, the dancers in the study had an abnormally low level of body water.

\section{Literature}

1. Drabik J. (1999). Physical activity and health - benefits and risks. Wychowanie Fizyczne i Sport 4, 124-125. [in Polish]

2. Makowiec-Dąbrowska T. (2012). Influence of physical activity performed during work and in everyday life on the cardiovascular system. Forum Medycyny Rodzinnej 6(3), 130138. [in Polish]

3. Yu S., Yarnell J.W.G., Sweetnam P.M., Murray L. (2003). What level of physical activity protects against premature cardiovascular death? The Caerphilly study. Heart 89(5), 502-506.

4. Garbacik J., Węgrzyn E. (2008). Choreoteraphy as a form of movement treatment. Zeszyty naukowe. Prace Instytutu Kultury Fizycznej. Uniwersytet Szczeciński 570(25), 131-139. [in Polish]

5. Haboush A., Floyd M., Caron J., LaSota M., Alvarez K. (2006). Ballroom dance lessons for geriatric depression: An exploratory study. The Arts in Psychotherapy 33(2), 89-97.

6. Hokkanen L., Rantala L., Remes A.M., Härkönen B., Viramo P., Winblad I. (2008). Dance and movement therapeutic methods in management of dementia: A randomized, controlled study. Journal of the American Geriatrics Society 56(4), 771-772.

7. Puszczałowska-Lizis E., Pop T., Szymańska-Smoleń E. (2015). Influence of choreotherapy on the development of children with psychomotor retardation. Postępy Rehabilitacji 3, 21-28. [in Polish]

8. Cieślicka M., Napierała M., Pilewska W., Iermakov S. (2012). Status of morphological and motor skills of girls participating in modern dance classes. Pedagogika, Psihologia ta Medikobiologicni Problemi Fizicnogo Vihovanna i Sportu 10, 96-104.

9. Przednowek K.H., Kopeć D., Wojtuń-Sikora B. (2012). Assessment of the impact of music and motor exercises on the level of the sense of rhythm and the auditory-motor coordination in physical education students. Journal of Health Promotion and Recreation 2(4), 14-21.

10. Zabrocka A., Sawczyn S. (2010). The effectiveness of developing coordination motor skills in dancesport athletes in the initial stage of training. Rocznik Naukowy AWFiS w Gdańsku 20, 49-55. [in Polish]

11. Krakowiak H., Cabric M., Sokołowska E., Lewandowski A. (2008). Body structure and composition of short distance runners. Medycyna Sportowa 1(6), 24, 30-36. [in Polish]

12. Andrzejewska J., Burdukiewicz A., Chromik K., Pietraszewska J., Stachoń A. (2010). Morphological structure and characteristics of judoists' feet. Acta Bio-Optica et Informatica Medica. Inżynieria Biomedyczna 16(1), 21-24. [in Polish]

13. Kozłowska J., Cieślicka M., Muszkieta R., Napierała M. (2013). The influence of training on the physique of athletes practising selected combat sports. In M. Napierała, R. Muszkieta, M. Cieślicka, W. Żukow (eds), Determinants of physical, mental, and social health (pp. 110-120). Bydgoszcz, Poznań: Ośrodek Rekreacji, Sportu i Edukacji w Poznaniu. [in Polish]

14. Pilewska W., Pilewski R. (2008). The physique of female and male dancesport athletes. In E. Rutkowska (ed.), The relationship between sport and well-being (pp. 109-117). Lublin: Wydawnictwo Uniwersytetu M. Curie-Skłodowskiej. [in Polish]

15. Pilewska W., Pilewski R., Żukow W. (2013). Characteristics of the physique of highly trained Latin style dancesport 
athletes determined using the Perkal method. Journal of Health Sciences 3(8), 193-218.

16. Pilewska W., Pilewski R., Żukow W. (2013). Characteristics of the physique of highly trained standard style dancesport athletes determined using the Perkal method. Journal of Health Sciences 3(8), 153-178.

17. Poliszczuk T., Broda D. (2010). Somatic constitution and the ability to maintain dynamic body equilibrium in girls practicing rhythmic gymnastics. Pediatric Endocrinology, Diabetes and Metabolism 16(2), 94-99.

18. Nowacka-Chiari E. (2005). The physique of young female swimmers. Stupskie Prace Biologiczne 1, 127-133. [in Polish]

19. Smolarczyk M., Wiśniewski A., Czajkowska A., Kęska A., Tkaczyk J. (2012). The physique and body composition of students studying physical education: A preliminary report. Pediatric Endocrinology, Diabetes and Metabolism 18(1), 2732.

20. Pezala M., Zukow W. (2013). Somatic features of female volleyball players at Elementary School No. 31 in Bydgoszcz. Journal of Health Science 3(6), 007-018.

21. Pietraszewska J., Burdukiewicz A., Andrzejewska J., Stachoń A. (2012). Body fat level and distribution and body posture of professional soldiers and police officers. Problemy Higieny i Epidemiologii 93(4), 759-765. [in Polish]

22. Pilewska W., Pilewski R., Żukow W. (2013). Characteristics of body composition highly qualified dancres and dancers latin american style of dance sports in light of typology of somatic A. Wanky and Kretschmer. Journal of Health Sciences 3(5), 255-266.

23. Yannakoulia M., Keramopoulos A., Tsakalakos N., Antonia-Leda M. (2000). Body composition in dancers: The bioelectrical impedance method. Medicine and Science in Sports and Exercise 32(1), 228-234.

24. Stokić E., Srdić B., Barak O. (2005). Body mass index, body fat mass and the occurrence of amenorrhea in ballet dancers. Gynecological Endocrinology 20(4), 195-199.

25. Mihajlović B., Mijatov S. (2002). Body composition analysis in ballet dancers. Medicinski pregled 56(11-12), 579-583.

26. Hergenroeder A.C., Fiorotto M.L., Klish W.J. (1991). Body composition in ballet dancers measured by total body electrical conductivity. Medicine and Science in Sports and Exercise 23(5), 528-533.

27. Mišigoj-Duraković M., Matković B.R., Ružić L., DurakovićZ., Babić Z., Janković S. et al. (2001). Body composition and functional abilities in terms of the quality of professional ballerinas. Collegium Antropologicum 25(2), 585-590.

28. Fus D., Czarny W., Czaja R. (2015). An anthropology handbook for physical education students. Lublin: Wydawnictwo WSSP. [in Polish]

29. Pietraszewska J. (2001). Impact of sports participation on the physical development of youth. Studia i Monografie AWF we Wroctawiu 59, 7-16. [in Polish]

30. Skład M., Krawczyk B., Majle B. (1993). Effects of an intense annual training on body components and other somatic traits in young male and female rowers. Biology of Sport 10(4), 239-243.

31. Nowak M. (2012). The somatic development of rural boys and girls aged 6-19 from the Subcarpathian voivodeship against the urban series. Medical Review (3), 288-310. [in Polish]

32. Van Marken Lichtenbelt W.D., Fogelholm M., Ottenheijm R., Westerterp K.R. (1995). Physical activity, body composition and bone density in ballet dancers. British Journal of Nutrition, The Nutrition Society 74(4), 439-451.

33. Perenc L., Radochońska A., Błajda J. (2016). Somatic growth in children and adolescents from Rzeszów aged 4-18 years and its variability over a thirty-five year period from 1978/79 to 2013/14. Medical Review 14(3), 244-265.

34. Burdukiewicz A., Andrzejewska J., Miałkowska J., Pietraszewska J. (2009). Physical development of children and youth from Wrocław aged 7-18 years. AWF Wrocław 10 , 57-58. [in Polish]

35. Lourens T. (2012). Anthropometric measurements of female adolescent ballet dancers. A research report. Faculty of Health Sciences, University of the Witwatersrand, Johannesburg.

36. Burdukiewicz A., Andrzejewska J., Pietraszewska J., Chromik K., Stachoń A. (2012). Body composition during puberty assessed using bioeletrical impedance. Acta Bio-Optica et Informatica Medica. Inżynieria Biomedyczna 18(1), 15-19. [in Polish]

37. Kolmaga A., Zimna-WalendzikE., Łaszek M., NiedźwiedzkaStadnik M., Trafalska E., Szatko F. (2013). An assessment of the nutritional status of 16-year-old youth from secondary schools in Łódź. Problemy Higieny i Epidemiologii 95(1), 9397. [in Polish]

Submitted: April 27, 2017

Accepted: June 19, 2017 